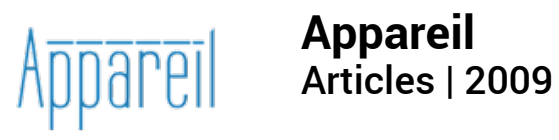

\title{
Alberti, Vasari, Leonardo, from disegno as drawing to disegno as projective milieu
}

Jean-Louis Déotte

\section{Q OpenEdition}

Journals

Electronic version

URL: http://journals.openedition.org/appareil/604

DOI: 10.4000/appareil.604

ISSN: 2101-0714

\section{Publisher}

MSH Paris Nord

Electronic reference

Jean-Louis Déotte, «Alberti, Vasari, Leonardo, from disegno as drawing to disegno as projective milieu », Appareil [Online], Articles, Online since 16 January 2009, connection on 31 July 2020. URL http://journals.openedition.org/appareil/604 ; DOI : https://doi.org/10.4000/appareil.604

This text was automatically generated on 31 July 2020 .

\section{(c) $)(9)$}

Appareil est mis à disposition selon les termes de la Licence Creative Commons Attribution - Pas d'Utilisation Commerciale - Pas de Modification 4.0 International. 


\title{
Alberti, Vasari, Leonardo, from disegno as drawing to disegno as projective milieu
}

\author{
Jean-Louis Déotte
}

1 1) The main contribution of Rancière's aesthetic (Le partage du sensible, 2000 - The Distribution of the Sensible, 2004, Le Destin des images, 2003 - Future of the Image, 2007, Malaise dans l'esthétique, 2004 ) consists in showing that in and of themselves the arts are not essential in the sense that each art, during the course of history, has been characterized in quite different ways. According to him, what gives the arts their properties are the rhetorical 'regimes' in the broad sense of the term (ethical: Plato, representative: Aristotle, aesthetic: Flaubert). These regimes offer a site for social and political struggle, which divide the "sensible" , because for political players to come into being they must appear in a public arena that they configure anew each time according to these sensory regimes. The arts are therefore implicated in a "struggle for the organization of the sensible" to use Stiegler's expression (Colloquium at Cerisy, 2004).

2 2) But this primacy of rhetoric is itself quite classic, it's the idea that poetry founded the fine arts. Rancière in his combat against the notions of "modernity" and the "avant-garde", in his systematic struggle against Lyotard, who he reduces to promoting a Kantian sublime, must also combat on another front. Indeed he must reject that technical revolutions could have some influence on the definition of the arts, he would reject the Benjaminian idea that there have been revolutions of a shared sensibility, revolutions provoked for example in the $19^{\text {th }}$ century by the "mechanical" arts such as photography or cinema (Le partage du sensible, The Distribution of the Sensible). Thus the idea that there have been and will again be cultural revolutions, that arediscontinuities,integral to semio-technical revolutions. Significantly in the work of Rancière, Aristotelian mimésis acts in the background as a principle of continuity for the history of western culture since the Greeks, enabling an account of classical Greek tragedy, as well as the perspectival representation theorized by Alberti and 
Hitchcockian cinema (La fable cinématographique, 2001, Film Fables). Thus there is a paradox in Rancière's work from which one can start afresh, if we take seriously the fact that there is history, a history of the arts, and thus discontinuities that can't be ignored in the history of culture as Lefort, Lyotard or Kracauer and Benjamin all evoke.

3 3) Discontinuities exist because the arts are "apparatused" (framed - appareillés), from one epoch to the next, by semio-technical devices that are the conditions for these arts. But these epochs are quite highly differentiated, configuring the arts as well as their reception, knowledge as well as the way in which beings appear, inscribing themselves in much longer temporalities which are surfaces of inscription. It's currently more or less possible to distinguish three surfaces of inscription, according to the norms of legitimacy that are integral to them. These surfaces have successively imposed themselves, which hasn't prevented them from co-existing, and enables them to be superposed, even causing conflicts or cosmetic différends to arise. Because each one, which is considered a fact, finds its legitimisation in being a type of right, according to a norm of legitimacy. Since the Lyotard of The Differend (1983), it's possible to isolate three norms of legitimacy, three important relations to the law, to power and to knowledge.

4 a) When the (savage) law is totally heteronomous, external to being-together (êtreensemble) and the singularity, the norm of legitimacy becomes narration, which is its apparatus (appareil): the narrative, and the privileged surface of inscription is the body, the human body, a surface of artefacts. For Lefort (Formes de l'histoire, 1978), heteronomy signifies that in this era of law and therefore of the surface of inscription, society has no influence on the law which always predates it, because it is given by the mythical "forefathers". The narrative in general, and myth in particular, are the focus of this narration that exposes the conditions of how the law is given. The ritual is its literal application, the law isn't meantto be commentated upon, but to be applied in its strictest and most literal sense, until the Being corresponds point by point to regulated-being(forced-being?) (devoir-être). Now, it's possible to characterize the "savage" society (according to Clastres' use of the term, La société contre l'Etat, 1974) saying that it is against the State, but also against self-rule and democracy because the body and arts have always and definitively been "apparatused". A society without promise and without projects because it repeats its nature which is the Good.

b) When the law is revealed (monotheistic religions) or integral to the existential journey of a sage (Buddha), then it is destined to be commentated upon indefinitely in the margins of the sacred text. In monotheistic religions, the giving passes by the inscription of the law of the infinite in a finite book, that for this reason becomes sacred, thus entailing the need for a mediator (writer or not) through whom the infinite is inscribed in the finite. This figure of the mediator can be the "son of God", God in human form. In Christianity this figure receives a special theologico-political determination, that of the incarnation and therefore of the embodiment (incorporation). The embodiment of the law was imagined by Saint Paul as "circumcision of the heart". There is no sphere autonomous from politics and the arts, the community should be incorporated into the body of Christwhich in turn must penetrate each believer according to the "theologico-political" schema of a double inclusion. In monotheistic religions, the need for a mediator entails witnesses of the mediator who will relate his words and his great acts. It is religions that have an aspect of witnessing (the Evangels, etc) and therefore the interpretation of witnessing. The arts (painting, sculpture, 
architecture, etc.) are the visible side of the legible sacred text. The hope is carried by the effective creation of regulated-Being (devoir-Etre).

6 c) When the law is said to be autonomous, the society gives its own lawwhose place of enunciation, which is empty, is ideally situated "among men" (Lefort). It's the condition of an indefinite deliberation on the laws that it agrees to adopt. In modern conditions, not the ancient ones of deliberation, representation is vital (Crignon on Hobbes, thesis). Everything happens as if the separation brought about by the footlights of Italian-style theatre became the condition of politics and knowledge: a transfer of power took place from the represented to the representatives, the represented were in the audience and the representatives on stage. In this framework, the representatives (the politicians, and in their respective domains, the artists and the scientists) have an essential role in declaring new laws and therefore constantly reconfiguring being-together. The figure of the representation that imposes itself gives presence to what wasn't, or what was only hollow, didn't have any substance or proper identity: being-together and singularity. The city-state of Florence in the $15-16^{\text {th }}$ centuries doesn't have any substance other than that accorded a priori by the paintings in perspective of the city and the dome of Santa Maria del Fiore by Brunelleschi. We must not look for in representation what comes after naked presence, the presence of a people always already there who would represent themselves after the fact ideologically and artistically.But, on the contrary, we must look for in representation, what allows presence, what configures it and thus separates it from itself: through disassociating from the outset representation and "immediate" presence. The structure of "presence", and hollow presence, is thus paradoxically representative. It's the representation that makes presence possible and not the inverse. It involves a political and artistic performance each time: the representatives perform being together, the representatives compensate for the drawbacks of the origin of being together through representation. This representation isn't necessarily parliamentary, it can be the existence of a simple spokesperson, of an abstract work. The main thesis, is that the One, to exist, must be divided, must be Two, according to very different modes. What distinguishes the modern public arena from the ancient one, in fact of this essential retro-projection, is the rejection already initiated by the Roman Empire of all political myths of autochthony as in Athens. The modern citizen is not the son of his MotherEarth (for example Athena), no more than he is integrated into the body of Christ. Since the Italian Renaissance and especially in Florence, the norm of deliberation is integral to the projective apparatus, particularly that of perspective. That's the reason why modern societies, which are representative, have always been in crisis and thus recorded in history. The regulated being having always had the natureof a project.

4) The distinguishable norms: narration, revelation, deliberation and their respective surfaces of inscription: the skin of human bodies and artefacts, the incarnation or embodiment, scientific objectification of bodies, are integral to the archi-apparatuses that become the milieux ("milieu" as both the centre and the environment) for being together, préindividuel milieux (Simondon), before the individualizing differentiation into singularity on one side and collective on the other. It's in this sense that apparatuses are in the middle (au milieu) of the world. The norm of disclosure was created by different heterogeneous apparatuses: for Christianity, the oriental Byzantine icon is one example (Mondzain, Image, icône, économie, 1976), as is the gothic miniature that epitomizes medieval European painting, another example is Sunnite Islam's 
interdiction of representation that privileges calligraphy and a geometry applied to architectural decoration, and for Shiite Islam the figurative painting of suffering bodies, etc. (Lyotard: Discours, figure, 1971). The norm of deliberation, that objectifies everything on which it is possible to deliberate, is integral to the projection apparatuses. These are the "symbolic forms" (term borrowed from Cassirer with some modifications) that create the epoch and create a destination for the singularity and being together.

8 5) Many indices lead us to think the era of the projective and representative archiapparatus and therefore historic projective apparatuses of representation (camera obscura, perspective, museum, photography, cinema, analytical therapy, video, etc.) are quickly replaced by another era and another world that can be characterized by other terms (digitalisation of knowledge and archives and thus of memory, the transformation of the contents of knowledge of information acquired without Bildung (education), dematerialization of supports, simulation and no longer representation, separation of temporality in relation tothe cosmos, ubiquity of works, always available here and there, etc). It is a fact, the "ancient" projective apparatuses are reconfigured and synthesized according to the characteristics of a new milieu which Lyotard baptized paradoxically with the term "post-modern". It was an obvious paradox given that it referred to characterizing modernity by its capacity to present important political figures of being together (a narrative of the emancipation of the people according to the thinkers of the Enlightenment, from the proletariat as an "universal class" according to Marxism, to an absolutely unique people according to Nazism, etc.). The constitutive narrative of being together, or the intrigue (Ricoeur, Temps et récit, 1983 - Time and Narrative), become integral to modernity, understood as a narrative of alienation, a loss of identity, followed by emancipation, a self-reconciliation, that is to say as a text form of the realization of a project. We know that according to Lyotard, anti-Aristotelian that he was, (for whom the sensible is understood as resistance, irreducible to logos, in short an inverted Neoplatonism), a collapse of intrigue, without which, it seems, there isn't any subjective viewpoint, contributing to liberating the sensible for itself, by a sort of purification where art (painting) has the most important role(Que peindre? 1987). The discourse of emancipation isn't possible without the dimension of the project and representation, against which Lyotard wrote numerous texts (from Discours, figure to L'économie libidinale, 1974). In fact, the project perfectly characterises the temporality and the relation to being in this milieu generated by the perspectival apparatus. Lyotard should have characterized postmodernism (what he called "immatériaux") by the end of project and not by the end of the Great Narratives, those which don't challenge the sensible.

9 6) It can be said that with the perspectival archi-apparatus, perfectly described by Alberti when he wants to create rules for the three arts (painting, sculpture, architecture), the milieu in an initial sense (knowing what supports and is located "before" and "between" apperception and artistic production, preceding the division between the intelligible and the sensible, form and matter, being-together and singularity), has entered in an era so new that we could not have been conscious of it sooner, precisely when the synthesis is madeaccording to other norms and criteria. The synthesis from which the Renaissance proceeded has a name: disegno. At first sight, according to Alberti, drawing provides the foundation for the three arts, however it was separated from painting (colour), emancipated and totally "apparatused" by perspective. In other words, if the apparatuses are the condition for the arts, then the 
perspective would have "apparatused" painting, sculpture and architecture, like it would have done for theatre (Italian-style staging, the Theatre of Vicenza, Palladio), urban planning (in particular Florence under Lorenzo di Medici), privileging drawing through which it was also presented (the treatises of perspective). Even so, it would have apparatused knowledge and know-how (from the Galilean kinematics to Cartesian geometry, from botany to anatomy (modern sciences), from stone cutting to geography (Map of Rome by Alberti), from archaeology to knowledge of the literature of the Ancients, to politics (Machiavelli) and finally to philosophy (Descartes, Hobbes), without forgetting the treatises on art (Trattatistica)). Thus paradoxically, it's an artistic technique that is privileged, disegno, drawing, that would become an autonomous art when collectors started desperately trying to get their hands on the sketches of Treatises that were recovered in the Albertina of Vienna. But this technique constitutes the matrix of knowledge and know-how, their new site,since the best translation that one can give the terms eidos and form, inherited from the double Greek tradition dating from Plato and Aristotle, is disegno. As J. Ciaravino demonstrated, the notions of idea (the famous idea hypostasized by Panofsky: Idea, contribution à l'histoire du concept de l'ancienne théorie de l'art, 1924), like the notion of Plato's eidos, Aristotle's form, concept, with all the antonyms and opposites possible (sensible, matter, etc.) are recovered, absorbed, reconfigured by something that isn't a concept, because disegno, is also a technique: an action of thought, the trace of this action, the plan of this action and final work, that is its archive.

Ciaravino: "Disegno is the spirit, the idea, the intention, the drawing, the project, the structure, the support, the sheet of paper, the black of the line, the line on white, the line alone. It is also the beauty, the quality, la bella maniera, the criteria of evaluation... It is the sketch, the outline, the rendering, the work itself. It is the work even before it exists; it is the work that already exists. It is the shadow of the image that will spread across the surface and the completed image already before our eyes. It is the transparency of the work that is revealed in all its perfection, the opacity of emptiness from which it appears. >>

Disegno reaches designing: simply the beauty, the pleasure and the enjoyment that creates harmony, the perfect harmony between the varied elements of the picture; on the other hand the validity of the formal structure of the work. As a general rule, the term disegno, isolated, refers to the foundation of the arts or indeed to the expression of the idea which is achieved by this means. When the term is followed by colorito, the two notions being distinguished, the term lends itself to be read as contour, like a linear frame that establishes the first, but not the ultimate power of the work. When the term is followed by giudizo, it refers above all to the general quality of the work, to the capacity that only the artist has to createan interpretation of the subject of the work. Disegno alone relates to all aspects of the arts; accompanying other terms and adjectives, it designates expression, talent, quality, the different characteristics of the work, also in relation to the reaction of the viewer." (Un art paradoxal, La notion de disegno en Italie aux XV-XVIè, p. 160, 2004)

Disegno has a unique role, because it is both an artistic technique and cognitive and at the same time a milieu and epoch (what we will call Humanism, or at least an InitialHumanism) that constitutes the spine of the new surface of inscription, a role that can be attributed today to the notion of information or to that of immatériaux so dear to Lyotard. It's possible, furthermore, to hypothesize that it's because Lyotard introduced in his thesis Discourse, figure, a long analysis of the epoch of perspective as a "block of writing", that he was able to identify by 1985 what was still in limbo: our milieu and our epoch. 
11 We must give a holistic sense to it, we could say that the sense of being was disegno, because beings, like all activities, experienced its supremacy. Then Disegno became an international destination.

12 7) Disegno would have been the sense of sense, but because it is irreducible to a single domain of signification and since it is also a practice that doesn't distinguish between a drawing and design, between abstract delineation and practical configuration. Designo is not only an idea, nor the idea of idea, because it comes from a gesture. It's not a sign, nor the sign of sign (in the linguistic sense) in spite of it's etymology (designare = to designate) because there is a thickness (graphic and therefore plastic) and thus it is related to the Lyotardian figural. Ultimately, it's like a contour that would be a colour (a hachure surrounding a figure that is about the light-dark, that forms a shadow, a non-configured colour according to Leonardo). Thus we must not confuse it with the symbol (which is, of course, a drawing but with a fixed signification), because as a work of art it is always being interpreted in new ways. Disegno isn't univocal. A buon disegno respects the laws of proportion, it starts with a form, from a totality, but it can also be a fragment, a sketch, a "future project" as wrote the Romantics of Jena. If, in a certain number of Treatises, there is opposition to colours, in the work of Leonardo, the patch of colour (macchia) has all the properties of a disegno since it functions like a support for projection for the artist lacking inspiration, the patch being this non-form where figures can appear.

8) The attempt by Panofsky (Idea, opus cited) to subsume all the meanings of disegno under the notion of Idea (a synthesis of the Platonic eidos and the Aristotelian form) could not succeed, because it wanted to join what has the nature of the subject with that of the nature of the object, while remaining immersed in metaphysics.

But at the same time, Panofsky challenged the common idea (which would be taken up again by Cassirer in his important book on the Renaissance: Individu et cosmos dans la philosophie de la Renaissance (1927)) of a philosophical supremacy of Neoplatonism (Ficin) in making an unnecessary gesture towards empiricism. On the other hand, the Idea understood in this manner isn't reducible to a drawing strictly created after the fact from a visible thing. Moreover, the opposition subject/object only means something due to the imposition of the perspectival apparatus onbeing-together and on the singularity, on one hand, like on things on the other. But Panofsky's stroke of genius consists of asking the question of milieu or of the "between" (entre), between subject and object, outside of the philosophical references inherited from the classics. What helps him here is his excellent knowledge of Dürer and hisengravings that enable us to see devices of perception in operation.

15 It was inevitable that such a reflection on milieu (of the between (entre), and this will be the second meaning of "milieu") raises the question of medium, this medium resulting in subjects like objects, facing each other. In 1927, the articulation (one of the meanings of the Greek word logos) between the two entities will become the phenomenon of a "symbolic form": perspective. This assignation (still hidden behind the mask of a philosophy of language) will constitute a genuine epistemological revolution since the idea ("universal judgement" in the text of Vasari) can only be understood from a geometry of proportional triangles.

16 9) Perspective is only "legitimate" because it is "artificial", geometrical, that is to say not natural, because it doesn't theorize the optic, unlike the way of producing Greek sculpture and architecture. What separates the two "perspectives", is the decision 
taken by the Renaissance (its essential invention): that the support of disegno should be transparent because it involves a plan of projection. It's from here that the choice of paper as the preferred material support comes. What we then add (thanks to Lyotard) to the "milieu" of the Renaissance, and that doesn't appear in the long list of meanings of disegno like "milieu", is that these drawings can only be inscribed on a plan of projection that isn't an opaque screen, that isn't a support for inscription like the sacred book is or the "savage" body. What is therefore already very immaterialised and digitalised. That's the reason why Vasari can speak of "universal judgement", because he knows disegno doesn't exist without the plane. Disegno has already fallen under the law of digitalisation, he knows the famous layout of Rome carried out by Alberti according to alphanumerical coordinates (Descriptio urbis Romae, 1445-1455 (?)).It's only because of this that the drawer's sketches can be an instrument of knowledge and artistic production.

10) The philosophical references coming from Neoplatonism (Ficin) such as alchemy or astrology might have been dominant (Cassirer), and constituted the "common philosophy" of the Renaissance, but it doesn't change the fact that they weren'tcontemporary to the perspectival apparatus. It would take Descartes, or even Kant, that is to say two or three centuries later, for philosophy to be contemporaneous with the apparatus of its epoch. Philosophy always comes after the apparatus because philosophy exposes the axioms. It is the same today, academic philosophy is totally out of step with the new digital "milieu".

18 11) But there is still a distinction to be made: if the perspective apparatus framed the epoch (faire epoch), it's according to the following paradox: there is a historic beginning and yet it always remains (in the same manner in which there are always believers in Judaism, Christianity or Islam, just like there are always "savages"), it is obvious for the projective apparatuses that still coexist. It isn't the same for the "milieu". If disegniowas a milieu, it's firstly that it was between all the pairs of oppositions (from form to matter, etc.) and because of this it put them all into circulation and communication: resulting in its dissemination. In certain respects, responding in this way would enable the articulation of what has never been and probably will be no more (for example: to thinking through drawings). Secondly, this power enabled disegno to constitute a milieu, but this milieu, like all milieu, is both geographically and historically delimited. Disegno was the milieu of Florence in the $15^{\text {th }}$ and $16^{\text {th }}$ centuries. Today, it's a research subject for art historians, it belongs to this domain of "the last things before the last" as Kracauer specified in relation to history (History: The Last Things Before the Last, 1969). But history cannot be reduced to the positivism of historicism. A certain régime of ideality inaugurated by disegno always endured, precisely as ideality. This is obvious in the European philosophy of science developed by Husserl (Krisis). It is perhaps easier to understand the articulation of the norm of legitimisation of "deliberation" of "democratic and capitalist" modernity (cf. Lyotard, Le Différend) with the definition of the surface of inscription in terms of project. It's possible to return to the distinction between the "representatives" and the "represented" that we limited to the political sphere and distinguish it from the sphere of theologico-political incarnationembodiment, and that of "savage" heteronomy. Because the project isn't the interpretation of a revelation, even if we limit ourselves to drawing (it's not a gothic miniature), nor the literal inscription an already existing law (loi déjà-là). The "representatives" create a temporality of the achievement which is a formal 
conception that must be followed by a material execution according to the constitutive model in the West for doing architecture. This demonstrates that the project has a fundamental value (arché) because it structures the future. Since then, temporality induced by the projective era is that of the achievement of an ideality, that is to say an idea that opens an ideal (like Kant's idea of reason), which implies that the effective achievement is always judged according to the ideal that it won't be, by definition, accomplished. It's the reason why, among others, the Lives of the artists written by Vasari progresses in function of an inadequacy of each work in relation tothe ideal: one painter follows another according to a progressive temporal vector. Disegno immediately possesses this authority and legitimacy which is that of an architectural drawing on a building site: even if in previous epochs architecture was always projective (we can imagine this was the case for the construction of the pyramids), the project can not be dissociated from the execution, evolving in relation to the work (this was true of the construction of cathedrals). This is the reason why architecture, like painting and sculpture, became the liberal arts, disegno is related to knowledge (of the spirit), thus an autonomous programme (for example : projects for utopian cities, real war machines - apparats in the words of G. Martini - to the radial structure). As we know, since the Renaissance, disegno is accompanied by models, it was almost only that (J. Boulet). The "political" representatives were thus model makers: practical thinking proceeded by volumes, from where the importance of models in the aesthetico-political avant-gardes of the beginning of the $20^{\text {th }}$ century comes (from cubism to the Bauhaus of Moholy Nagy including Suprematism to Nicolas Schöffer, etc.). We can even wonder if some contemporary architecture isn't basically commemorative, taking the form of full-scale models (Les Folies by Tschumi in the Parc de la Villette, Frédéric Borel in Menilmontant)?

Our political representations were at the base aesthetic: models (which can be collected, like at the FRAC Centre). The "modern" political gesture was always that of circumscription and construction: the condition for drawing and design, image and project, line and intention. But what remains of that today? A programme, in any sense of the word, isn't a project, because it is destined to end with its actualisation, which will never be the case with a project. Of course the alphanumerical programme was one of the elements of disegno (the famous map of Rome by Alberti), but it finally supplanted it by imposing on the era of "immatériaux" an uni-dimensionality and a mono-directional temporality. Thus representation which scarcely has any meaning, risks giving a "naked presence" to itself, without mediations. Certainly the "programme" could have been conceived beforehand as a declination of the project, its concretisation, a political project giving rise to a set of measures that were programmed. But when a genocide was programmed in the $20^{\text {th }}$ century (for example, the extermination of the "Jews" of Europe or the extermination of the Tutsis by the Hutus in Rwanda both followed a plan cleverly calculated and put into operation), we clearly understand that it's about something quite different than a project, even an insane one, because the dimension of the ideality of the idea has, itself, already, been annihilated. What makes the difference, isn't the intention (that exists in every project), it's the systematisation or instrumentation of reason to adapt Adorno's manner of speaking: the nature given must be totally applied, in the smallest nooks and crannies of reality, there must not be any remains: the Nazis went looking for the "Jews" in the furthest corners of Europe, as far as Thessalonia. That has nothing to do with the project of the conquest of a territory, with all the destruction that involves, like in the 
case of the "conquest of the West". It's enough to read the Worker by Jünger: which outlines the programme of total mobilisation of a people according to the Type of worker. But this Type isn't a representation, it's closer to what Porchet shows with social engineering without limits. I would propose therefore to say that a Type relates to an ontotypology (Lacoue-Labarthe) and that characterizes post-totalitarian societies.

\section{NOTES}

1. The 'sensible' does not refer to what shows good sense or judgment but to what is aisthèthon or capable of being apprehended by the senses. [le partage du sensible $=$ the partition/distribution of the sensible - refers to the implicit law governing the sensible order that parcels out places and forms of participation in a common world by first establishing the modes of perception within which these are inscribed. The distribution of the sensible thus produces a system of self-evident facts of perception based on the set horizons and modalities of what is visible and audible as well as what can be said, thought, made, or done.]

\section{ABSTRACTS}

It can be said that with the perspectival archi-apparatus, perfectly described by Alberti when he wants to create rules for the three arts (painting, sculpture, architecture), the milieu in an initial sense (knowing what supports and is located "before" and "between" apperception and artistic production, preceding the division between the intelligible and the sensible, form and matter, being-together and singularity), has entered in an era so new that we could not have been conscious of it sooner, precisely when the synthesis is madeaccording to other norms and criteria. The synthesis from which the Renaissance proceeded has a name: disegno. At first sight, according to Alberti, drawing provides the foundation for the three arts, however it was separated from painting (colour), emancipated and totally "apparatused" by perspective. In other words, if the apparatuses are the condition for the arts, then the perspective would have "apparatused" painting, sculpture and architecture, like it would have done for theatre (Italianstyle staging, the Theatre of Vicenza, Palladio), urban planning (in particular Florence under Lorenzo di Medici), privileging drawing through which it was also presented (the treatises of perspective).

$\mathrm{Au} \mathrm{XV}^{\mathrm{è}}$ et XVI ${ }^{\mathrm{è}}$ siècle en Italie des artistes comme Alberti, Léonard de Vinci, etc, vont du fait de l'imposition qui va se généraliser de l'appareil (apparatus) perspectif, redéfinir le dessin dans ses rapports aux autres arts (peinture, architecture). Le dessin va d'une part devenir le modèle des arts de l'espace, mais surtout, sa compréhension, en termes de disegno, va déborder largement le champ artistique pour influencer la philosophie. Le concept va être défini selon la prérogative du disegno, la temporalité de l'action va devenir celle du projet, qui n'est pas un programme. 
C'est dire que l'ère projective à laquelle nous appartenons toujours en partie s'enracine toujours dans une sensibilité commune qui nous fait toujours voir dans un dessin, une réalité possible.

INDEX

Mots-clés: appareil, architecture, dessin, disegno, dorsale de la sensibilité, Panofsky, peinture, perspective, préindividuel, programme, projet, Rancière, Simondon

\section{AUTHOR}

JEAN-LOUIS DÉOTTE

Professeur de philosophie, Université de Paris 8 Saint Denis 